\title{
Evaluation of rainfall and wetland water area variability at Thirlmere Lakes using Landsat time-series data
}

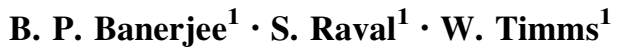

Received: 23 September 2015/Revised: 3 April 2016/Accepted: 18 May 2016/Published online: 2 June 2016

(C) Islamic Azad University (IAU) 2016

\begin{abstract}
Thirlmere Lakes is a group of five freshwater wetlands in the southwest fringe of Sydney, Australia, that is subject to cyclic wetting and drying. The lakes are surrounded by activities that have led to increasing pressure on the local surface and groundwater supply including farming and mining. The mine has been operating for more than 30 years, and in recent times, there has been speculation that the surface subsidence and underground pumping may have some impact on surface water and groundwater hydrology. A study was undertaken using satellite imagery to examine the relation between water area changes and rainfall variability. The study utilised Landsat time-series data during the period 1982-2014 to calculate changes in the lake water area (LA), through the normalised difference water index (NDWI) threshold. High classification accuracy was achieved using NDWI against high-resolution data that are available for the years 2008 $(88.4 \%), 2010(92.8 \%)$, and $2013(96.9 \%)$. The LA measurement was correlated against 11 historic observations that occurred in 2009, 2010, and 2011 during drier wetland conditions. Correlation analysis of the LA with the residual rainfall mass spread across the past 30 years has found that rainfall variability is a major dominant factor associated with the wetland changes. The underground mining operations, if verified by independent investigations, probably play a minor or negligible contributor to variations in total wetland area during the study period.
\end{abstract}

S. Raval

simit@unsw.edu.au

1 Australian Centre for Sustainable Mining Practices, School of Mining Engineering, The University of New South Wales, Kensington, Sydney, NSW 2052, Australia
This study has demonstrated that remote sensing is a technique that can be used to augment limited historic data.

Keywords Wetland monitoring · Remote sensing · Long-term monitoring · Time-series analysis · Landsat

\section{Introduction}

Wetlands are an important part of water systems and have often been considered as one of the most fragile type of ecosystems (Shanbhag and Borges 2008). Changes in wetland ecosystems are often unpredictable, and challenging to map and quantify. Relatively small disturbances to ecosystems have the potential to significantly affect natural wetland functions. Variability of the wetland water area depends on rainfall (Conway et al. 2005) though this relationship may vary from one site to another (Kebede et al. 2006). The Thirlmere Lakes in New South Wales of Australia (Fig. 1) includes sensitive wetlands where the water level has been reported to have fluctuated significantly over the years (Riley et al. 2012; Schädler 2014). The Thirlmere Lakes is situated within the Southern Coalfield, where an adjacent underground longwall mine has been operating since 1979 (Kay et al. 2006). Jenkins and Frazier (2010) have claimed that underground longwall mining can be a potential threat to wetland environments. Surface subsidence, which is often associated with the extraction of the longwall panels, could potentially change the landscape overlying the extraction panels (Booth 2006; Guo et al. 2008). Changing surface slopes and fracturing of the ground may alter rainfall runoff pattern, soil moisture, seepage losses, and groundwater recharge (Booth 2006; Jenkins and Frazier 2010). Murray et al. (2003) claimed that mining can induce changes in soil, water, and 


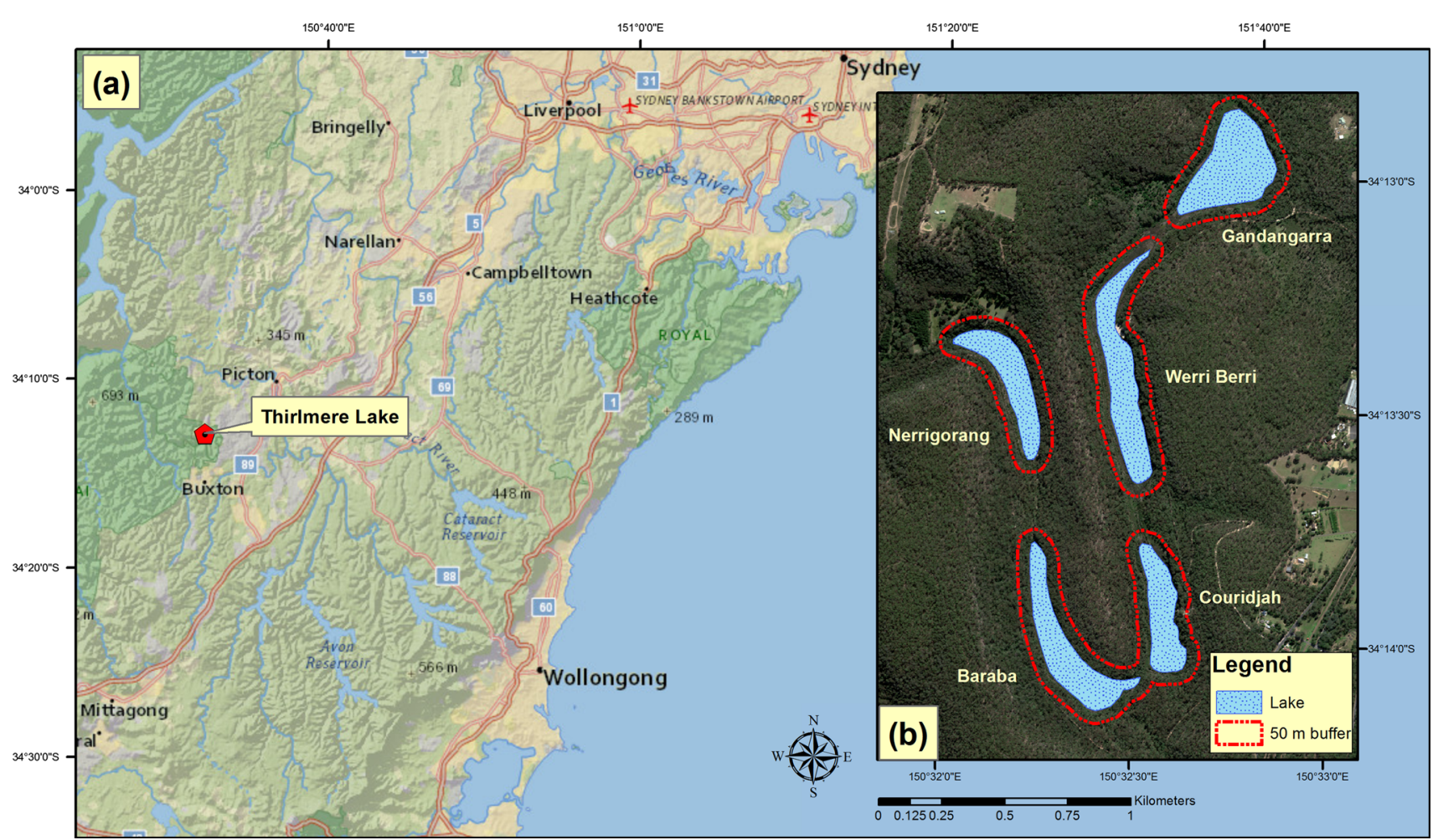

Fig. 1 a Location of the study area. b Satellite view of the Thirlmere Lakes and surrounding vegetation (sensor: Worldview-2) (date of acquisition: 01/04/2010)

groundwater, which may also impact ecosystems within and adjacent to the lakes. With recent drying of the Thirlmere Lakes, TCPL (2012) examined the possibility that mining operations may have changed groundwater storage and flow, and contributed to decreased water levels. However, evaluations of surface water and groundwater hydrology have not been able to form a direct link between mining activity and its impact on adjoining wetlands (Riley et al. 2012). Significant gaps in baseline data and in understanding of possible processes have contributed to considerable uncertainty (BMCS 2012; Pells 2011). The sensitivity of the lakes has led to a call for continuous monitoring to help define and understand changing conditions within the wetland ecosystems (Mooney et al. 2005).

This study is unique in that it has been able to consider the long-term changes in the Thirlmere Lakes water area (TLWA) over a 28 -year period based on the remote sensing technique. A series of 162 Landsat observations acquired between 1987 and 2014 inclusive were used to calculate changes in TLWA for comparison against rainfall data. This equates to, on average, six determinations of the lake area each year. In this study, TLWA is used synonymously to refer to wetlands and surface water area of the lake. The normalised difference water index (NDWI) threshold was used to compute lake water area (LA) of the wetland from the imagery. The accuracy of the classification was assessed against high-resolution remote sensing dataAirborne Digital Sensor (ADS-40), WorldView-2 (WV2) - and images from Google Earth. The TLWA calculation for a dry period (2010-2011) was validated with 11 historical observations. Changes in the wetland area and local rainfall data were then statistically analysed.

\section{Current status of wetlands}

The international Ramsar wetland conservation treaty defines wetlands as "areas of marsh, fern, peatland or water, whether natural or artificial, permanent or temporary, with water that is static or flowing, fresh, brackish or salt, including areas of marine water the depth of which at low tide does not exceed 6 m" (Wang and Weng 2013). Although the definition of a wetland can vary between the different authorities, essentially wetlands are large tracts of land that is saturated with water, reflecting an intersection of land and water ecosystems (Wang and Weng 2013).

Wetlands are considered to be relatively productive units of the surrounding ecosystem. Wetlands are important for water purification, as part of the carbon cycle, and for climate regulation, flood control, shoreline stability, recreational opportunities, and tourism. In addition, wetlands provide shelter to a wide range of fauna such as fish, amphibians, reptiles, mammals, monotremes, insects, and 
invertebrates (Barbier et al. 1994; Daily 1997; Wang and Weng 2013). Accurate global assessment of wetland area has always been a challenge, mainly due to lack of precise mapping tools and protocols. Millennium Ecosystem Assessment (Mooney et al. 2005) conservatively reported there is about 12.8 million square kilometres of wetlands on the earth's surface. The importance of wetland systems are often neglected compared with development needs (Ghatak 2010). Human disturbances and encroachment by human activity including industrialisation, over-grazing, mining, unplanned artificial drainage, and unsustainable water usage have induced ecological stress to wetland systems (Mooney et al. 2005; Ramsar Convention Secretariat 2011, 2013). Water scarcity, threatened species, disruption of breeding grounds, sediment load imbalance, and improper nutrient filtration are some of the common induced stresses (Mitsch and Gosselink 1994; Mooney et al. 2005). A trend of reduced wetland areas in many parts of the world (Mooney et al. 2005) indicates the stresses imposed on wetland ecosystems.

Mining operations have the potential to be a threat to fragile wetland ecosystems if leading practices are not adopted during the design, operation, and closure stages of a mine. Jenkins and Frazier (2010) have documented threats to swamp environments in the Western and Southern Coalfields regions of the Sydney Basin associated with underground longwall mining. Mining-introduced heavy metal contaminations also impose ecological risk in wetlands (Vaezi et al. 2015). Concern has been raised regarding subsidence effects on wetlands, slope changes, contamination of groundwater, and soil moisture fluctuations (Booth 2006; Jenkins and Frazier 2010). Contamination of swamps could gradually reduce the net primary productivity of wetland ecosystems (Eamus and Froend 2006). Changes in hydrological regimes can lead to irreversible environmental degradation. The UN Millennium Ecosystem Assessment identifies environmental degradation to be most pronounced in wetlands compared with other aquatic or terrestrial ecosystems. Accurate and updated wetland inventories are essential to protect wetlands from degradation and to prevent damage (Ozesmi and Bauer 2002). Wetland environments, therefore, require frequent monitoring and mapping to underpin sustainable management.

\section{Remote sensing for wetland monitoring}

Conventionally, wetland mapping has focused on the determination of the extent of vegetation and identification of species (Moser et al. 1996) and has been conducted through field surveys and site inspections (Rundquist et al. 2001). Although these traditional techniques can provide detailed data, they were constrained by several limitations.
Field survey-based methods are not possible in inaccessible areas and elsewhere are often time-consuming and expensive (Harvey and Hill 2001; Rundquist et al. 2001).

Remote sensing techniques have the potential to provide synoptic coverage of wetlands, including those difficult to access, at a reduced cost (Rundquist et al. 2001). Moreover, information related to temporal changes that potentially affect the hydrological regime and water balance of the wetlands can be acquired using satellite images (Ozesmi and Bauer 2002). Importantly, satellite imagery can go back years and in some instances several decades. Different types of remotely sensed data have been used for wetland classification and monitoring over the past decade or so, including optical (Harvey and Hill 2001; Jenkins and Frazier 2010), radar (Baghdadi et al. 2001), and LiDAR (Jenkins and Frazier 2010).

The use of Landsat data for monitoring wetlands is the most prominent. Work and Gilmer (1976) pioneered the use of Landsat MSS data in 1976 to estimate the amount of surface water in a prairie pothole region of North Dakota. Landsat Thematic Mapper (TM) band $3(0.63-0.69 \mu \mathrm{m}), 4$ $(0.76-0.90 \mu \mathrm{m}), 5(1.55-1.75 \mu \mathrm{m})$, and $7(0.8-1.1 \mu \mathrm{m})$ are usually reported to be the best band combinations for wetland detection. Jensen et al. (1984) utilised Landsat TM imagery to detect changes in water levels in a coastal region of South Carolina. Sader et al. (1995) used Landsat TM data to map forested wetland with $82 \%$ accuracy. Dobson and co-workers found that simple band ratios such as B5/B2 and (B5 $\times$ B7)/(B5 + B7) are effective to separate urban areas from waterbodies (Dobson et al. 1995). Johnston and Barson (1993) were able to classify $95 \%$ wetlands and $50 \%$ of freshwater meadows through simple techniques such as density slicing on Landsat TM for Australian wetlands in the Skipton area.

Bortels and co-workers used Landsat TM and Enhanced Thematic Mapper Plus (ETM+) data acquired between 1989 and 2004 together with Advanced Spaceborne Thermal Emission and Reflection Radiometer (ASTER) images and visible and near-infrared (VNIR) images to perform a study over the Amvrakikos Gulf on the west coast of Greece (Bortels et al. 2011). The study indicated possibilities of tracing small wetland patches of around 0.5 hectare by performing an unsupervised iterative self-organising data analysis (ISODATA) classification. Kayastha and co-workers used a threshold for Chi-square distribution of z-scores upon NDVI values extracted from Landsat time-series data to map interannual changes from 1985 to 2009 in the wetland ecosystems in northern Virginia, with $89 \%$ accuracy in detecting the change (Kayastha et al. 2012). Tulbure and Broich (2013) used Landsat TM and ETM+ datasets from 1999 to 2011 to monitor spatiotemporal dynamics of wetlands along south-western coastline of Australia, with $96 \%$ overall classification 
accuracy. Shubho and co-workers employed an improved semi-automatic segmentation approach with Landsat TM images to map land cover (vegetation, wetland, and builtup area) changes in Dhaka, Bangladesh (Shubho et al. 2014). Their analysis showed a decreasing trend of wetland area, with $57.9 \%$ of area lost between 1989 and 2010.

More recently, $\mathrm{Na}$ and co-workers studied the significance of land use and land cover dynamics on the Zhalong wetland, China (Na et al. 2015). The multitemporal land use/land cover analysis was performed using Landsat MSS and TM datasets. In addition, the study also derived landscape matrices from Landsat MSS and TM datasets. The temporal variation of different landscape parameters was analysed against different land use/land cover classes. The study reported major impacts from anthropogenic sources (i.e. construction, agriculture, and industrial and human waste) in wetland spatial extent, landscape pattern, and water quality.

There is a need to investigate changes in water surface area of a wetland vis-à-vis variability of rainfall by applying remote sensing methods. Such investigations are particularly important to further investigate the causes of the changes and their linkage to human activities, such as underground mining and agriculture. The present study is the first attempt to evaluate long-term changes in surface water in Thirlmere Lakes wetland. This evaluation will help future studies to investigate and quantify the effect of anthropogenic factors including underground mining on the wetland.

\section{Study area}

The Thirlmere Lakes system is situated $90 \mathrm{~km}$ south-west of Sydney, Australia $\left(34^{\circ} 12^{\prime} 50.98^{\prime \prime}-34^{\circ} 14^{\prime} 08.67^{\prime \prime} \mathrm{S}\right.$, $\left.150^{\circ} 32^{\prime} 02.72^{\prime \prime}-150^{\circ} 32^{\prime} 54.29 \mathrm{E}\right)$ and comprises a group of five interconnected lakes and wetlands, namely Gandangarra, Werri Berri, Couridjah, Baraba, and Nerrigorang. The landscape is 15 million years old and has been designated as Thirlmere Lake National Park under the Greater Blue Mountains World Heritage Area (Riley et al. 2012). The 50 hectares of the lakes area is listed in the Directory of Important Wetlands in Australia (Riley et al. 2012).

The TLWA is surrounded with dense grass-like vegetation, followed by moderately thick forest cover, with eucalyptus trees unevenly clustered around various places. Topographic relief in the TLWA area varies by about $50 \mathrm{~m}$ within the catchment (TCPL 2012). Outcrops of Hawkesbury sandstone dominate the landscape of the valley sides, along with some outcrops of Wianamatta shale (Pells 2011). A thin, sandy, soil mantel and alluvium of up to approximately $30 \mathrm{~m}$ depth make up the upper valley sides and the lake bottom, respectively (Pells 2011).
In addition to climate variability, the Thirlmere Lakes has been subjected to various stresses including bushfire and weed effects on native vegetation, recreational boating and bank erosion (Timms 1992), nutrient and metal concentrations, water extraction for various purposes including local orchards, and possible dewatering and subsidence associated with underground mining of coal (Riley et al. 2012). Tahmoor colliery has been extracting coal from the Bulli coal seam at a depth of approximately $300 \mathrm{~m}$ below ground by longwall methods since 1981. The mining operations were approximately $660 \mathrm{~m}$ east of Lake Couridjah during the period 1996-2002 (TCPL 2012).

Lake water levels decreased significantly during the past decade, leading to speculation that underground mininginduced surface subsidence was a contributing factor ( $\mathrm{Ri}$ ley et al. 2012). The Thirlmere Lakes Inquiry was commissioned in 2012 by the NSW Government to examine the reasons for the low levels of Thirlmere Lakes (Riley et al. 2012). This inquiry was inconclusive in distinguishing various factors contributing to long-term declines in the lake water levels such as evaporation, changes in catchment area, groundwater pumping from the shallow aquifer by multiple local users, and the possibility of groundwater losses associated with mining. The inquiry noted that the Bald Hill claystone, at a depth of $100 \mathrm{~m}$ below the lake bed, limited the vertical rate of groundwater seepage. No evidence was found to link mining-induced surface deformation to the possibility of increased seepage losses from the TLWA. A further investigation to explicitly account for uncertainty in analyses and modelling was recommended (Riley et al. 2012).

Long-term changes in lake level identified from a compilation of historic data were attributed by Schädler (2014) primarily to anthropogenic factors including extraction of lake water for steam engines and for Picton Tuberculosis Village up to year 1910, and in more recent years to an exponential increase in the number of groundwater bores in the region, and to the proximity of longwall mining. The volume of groundwater extracted in the area is unknown. Statistical analysis identified change points due to declining water levels at the three lakes: Lake Werri Berri in 2004, Lake Couridjah in 2000, and Lake Nerrigorang in 1998. However, the change-point statistical analysis was based on data to 2012 and did not evaluate subsequent increases in lake levels after a decade-long drought.

Work by Pells (2011) and TCPL (2012) had reported the development of models for surface water and groundwater in the TLWA. The NSW Office of Water (NOW) reported that water levels in the Thirlmere Lakes had been low in the past for example during the Federation drought (1895-1903), the World War 2 drought (1937-1945), and the Millennium drought (Riley et al. 2012; van Dijk et al. 
2013). The Millennium drought (2001-2009) was particularly severe in south-eastern Australia (Tulbure and Broich 2013). One of the strongest climate drivers in south-eastern Australia is the El Nino Southern Oscillation (ENSO), related partly to temperature cycles in the Pacific Ocean, and linked to relatively dry (El Nino) and wet (La Nina) conditions (BOM 2015). The frequency, duration, and severity of droughts in the Thirlmere area are affected by El Nino cycles, although the Thirlmere Lakes Inquiry did not take El Nino cycles into account (NSW Government, Thirlmere Lakes Inquiry 2013).

Historic aerial photographs and records have been useful in understanding the long-term context of lake variability, despite their limitations. For example, aerial photographs show a high water level in 1955 when lakes Gandangarra, Werri Berri, and Couridjah were interconnected. However, a predictive hydrological model (TCPL 2012) developed in the past for the lake surface area and water levels was not reliable due to the limited number of historical monitoring data. This current study is the first to evaluate multidecadal Landsat imagery to quantify changes in TLWA. Furthermore, the onset of wetter climatic conditions during 2012 after a long drought has provided an ideal opportunity to re-evaluate the reasons for changes in lake area. A correlation analysis was also performed between TLWA and the rainfall to understand its relative influence in changes compared with other factors such as underground mining.

\section{Materials and methods}

Figure 2 outlines the methodology involved in this study.

\section{Data}

The study required use of Landsat time-series satellite data of Thirlmere Lake for detection of lake water surface area changes over time. The Landsat programme began on 23 July 1972 with the launch of Landsat MSS, the earth resource-monitoring satellite sensor. Since then, the United States Geological Survey (USGS) launched many other satellite sensors and has maintained a time-continuous archive of the acquired satellite images. The Landsat mission maintains an orbital revisit period of 16 days and provides almost complete spatial coverage of the global land cover (Irish 2000). Several studies on wetland monitoring were produced following the granting of free public access to Landsat data by the USGS (Bortels et al. 2011; Kayastha et al. 2012; Tulbure and Broich 2013). This study utilised Landsat data from TM, ETM+ and OLI sensors. Data from WV2 satellite's multispectral sensor, as well as airborne ADS-40 sensor, were utilised for the accuracy assessment.
A total of 1528 Landsat TM, ETM+ and OLI terraincorrected datasets (L1T) acquired between July 1987 and October 2014 were examined, and finally 162 images with less than $20 \%$ cloud coverage were selected for further analysis. Landsat ETM+ datasets after the scan line collector (SLC) failure on 31 May 2003 (Storey et al. 2005) are also excluded to avoid inaccuracies in surface water computation due to unavailability of every sixth spatial detector.

Daily rainfall data used in this study were acquired from the Bureau of Meteorology's Thirlmere Lake monitoring station (BOM 2014), located at latitude $33^{\circ} 30^{\prime} 36^{\prime \prime} \mathrm{S}$, longitude $115^{\circ} 38^{\prime} 24^{\prime \prime} \mathrm{E}$, and altitude $20 \mathrm{~m}$ above mean sea level. The station has been continuously monitoring rainfall since 1964.

\section{Pre-processing}

Raw data (tarfile) were extracted using Python codes and standard library modules. All the extracted datasets were then stacked and spatially reduced to create sub-images covering the TLWA.

A graphical spatial model was customised and batchprocessed to convert the raw digital number (DN) values of Landsat TM and ETM+ into radiance and then into top of atmosphere (ToA) reflectance using Eq. 1 (YCEO 2013).

$$
\begin{aligned}
L_{\lambda}= & \left(\frac{\operatorname{LMAX}_{\lambda}-\operatorname{LMIN}_{\lambda}}{\operatorname{QCALMAX}_{\lambda}-\mathrm{QCALMIN}_{\lambda}}\right) \\
& \times\left(\mathrm{QCAL}_{\lambda}-\mathrm{QCALMIN}_{\lambda}\right)+\operatorname{LMIN}_{\lambda} \\
\rho_{\lambda}= & \frac{\pi \cdot L_{\lambda} \cdot d^{2}}{\mathrm{ESUN}_{\lambda} \cdot \cos \theta_{s}}
\end{aligned}
$$

where $L_{\lambda}$ is radiance, QCALMIN $_{\lambda}$ is minimum quantized calibrated pixel value, QCALMAX $_{\lambda}$ is maximum quantized calibrated pixel value, $\operatorname{LMAX}_{\lambda}$ is spectral radiance scales to QCALMIN ${ }_{\lambda}, \operatorname{LMIN}_{\lambda}$ is spectral radiance scales to $\mathrm{QCALMAX}_{\lambda}, \mathrm{QCAL}_{\lambda}$ is the digital DN value, $\rho_{\lambda}$ is ToA reflectance, $d$ is Earth-Sun distance in astronomical units, $\operatorname{ESUN}_{\lambda}$ is mean solar exoatmospheric irradiance, and $\theta_{s}$ is solar zenith angle; all values are at respective wavelengths (ג).

Similarly, for Landsat OLI, Eq. 2 was used to convert raw DN to ToA reflectance (USGS 2013).

$$
\begin{aligned}
& L_{\lambda}=M_{\lambda} \cdot \mathrm{QCAL}_{\lambda}+A_{\lambda} \\
& \rho_{\lambda}=\frac{L_{\lambda}}{\cos \theta_{s}}
\end{aligned}
$$

where $M_{\lambda}$ is band-specific multiplicative rescaling factor, $A_{\lambda}$ is band-specific additive rescaling factor, and other symbols have their usual meaning.

Dataset-dependent variables such as solar zenith angle $\left(\theta_{s}\right)$ and date of acquisition (Julian day) were directly 


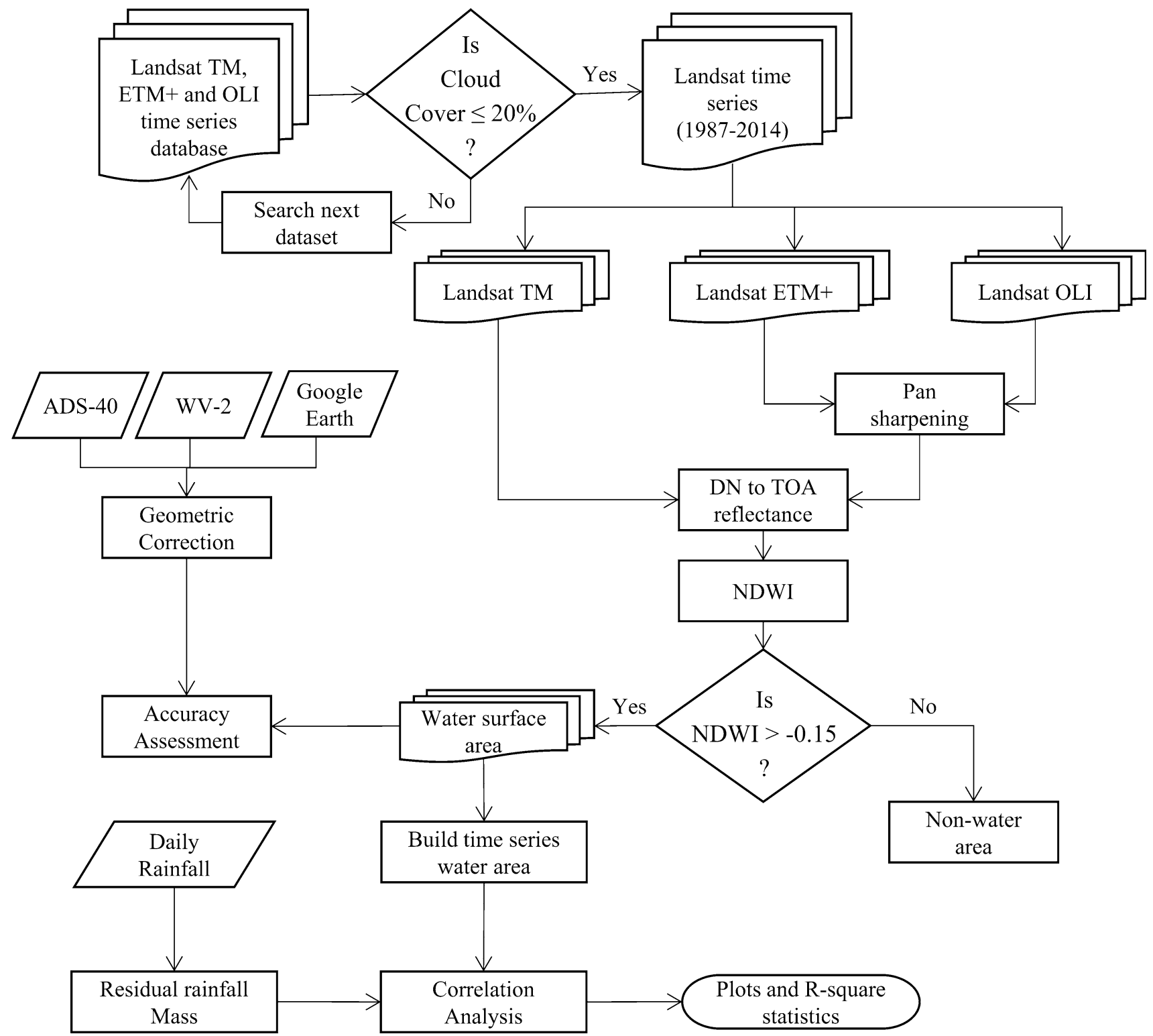

Fig. 2 Outline of the workflow

read from the metafile for corresponding use. Also, Earth-Sun distance $(d)$ and mean solar exoatmospheric irradiances $\left(\operatorname{ESUN}_{\lambda}\right)$ were easily imported from saved tables into the calculation. The technique was performed over all individual optical bands of Landsat TM, ETM+ and OLI datasets using the ERDAS batch-processing module. This eliminated the need to manually select, provide dataset-dependent values, and process each dataset individually. The Landsat ETM+ and OLI datasets were further pan-sharpened using Euler's method utilising the batch-processing feature to bring the resolution down to $15 \mathrm{~m}$. This was deemed to further increase the accuracy in computation of lake water area (LA).

\section{Normalised water index (NDWI)}

The processing involved utilisation of NDWI to measure surface water over the Thirlmere Lakes. NDWI is computed as per the Eq. 3 .

NDWI $=\frac{\text { Green band }- \text { NIR band }}{\text { Green band }+ \text { NIR band }}$

The robustness of the NDWI technique to only detect the LA was enhanced by selecting a buffer area mask of $50 \mathrm{~m}$ around the widest possible lake boundary (shown in dotted red in Fig. 1). Level thresholding of NDWI to detect multiple classes such as water, trees, grass, and soil often leads to a classification ambiguity; however, the technique 
was found suitable to detect only the LA (one-class problem) as required in this study. A threshold of -0.15 was found experimentally to accurately (Table 1) separate the surface water area from the surrounding landscape. The number of classified water pixels was counted and multiplied with the respective spatial resolution to compute the LA. The accuracy resulting from this classification technique is discussed in the results and analysis section.

\section{Lake water area and rainfall residual correlation}

Computed LA was used to generate a moving average curve with a window size of 365 days considering the limited number of observations posed by cloud cover. For the discontinuous measurements in LA, the first element of the moving average of LA was calculated taking the average of the available initial data points within the fixed window (365 days) of the series. The window is subsequently shifted forward along the series. Noisy fluctuation in the moving average curve was further filtered using a low-pass filter.

The average monthly lake water area $\left(\mathrm{LA}_{\mathrm{MA}}\right)$ was computed from LA. The units of $\mathrm{LA}_{\mathrm{MA}}$ and LA were expressed in hectares.

Firstly, residual rainfall mass $\left(R_{R}\right)$ was calculated for a month by subtracting monthly average rainfall $\left(R_{\mathrm{MA}}\right)$ from the monthly rainfall sum $\left(R_{S}\right)$. Then, a cumulative residual rainfall mass $\left(R_{\mathrm{RM}}\right)$ was derived.

$$
\begin{aligned}
R_{R} & =R_{S}-R_{\mathrm{MA}} \\
R_{\mathrm{RM}} & =\text { cumulative }\left(R_{R}\right)
\end{aligned}
$$

The units of daily rainfall $\left(R_{D}\right)$ and monthly rainfall and averages were expressed in mm. $R_{\mathrm{RM}}$ is a common and useful method to plot a time series of above- and belowaverage rainfall periods for comparison with other data. A decreasing or increasing slope of $R_{\mathrm{RM}}$ indicates relatively dry or wet periods, respectively. The starting point, and thus the absolute value of $R_{\mathrm{RM}}$, may vary, but the trends and timing of peaks or changes in slope may be significant in a hydrological context.

\section{Results and discussion}

A total of 162 Landsat TM, ETM+ and OLI datasets were used over a period of 28 years to detect surface water using NDWI. In the absence of available historic ground surveys, the accuracy of the classification was assessed through percentage of correctly classified points out of a total number of randomly generated ground truth points on the high-resolution reference images (ADS-40, WV-2 and Google Earth). Table 1 shows the classification accuracy of LA measurements that was achieved from the Landsat data compared to the high-resolution data.

The accuracy of the overall LA measurements derived from the Landsat data was further compared against the historical observation published records (Pells 2011) as well as unpublished record of the lake level measurements communicated by Peter Pells of Pells Consulting on 15 February 2016 (Pells 2016) as shown in Table 2. The lowest water level observed in individual lake by Pells was utilised to assume dry status for all the five lakes for this study. The derived LA time-series was found to be consistent with the observations in 2009, 2010, and 2011, where the TLWA was reported dry and the calculated maximum LA was found to be approximately zero.

A time-series plot of LA was highly variable; however, a linear decreasing trend was evident during the period of study from 1987 to 2014 (Fig. 3). The maximum and minimum LA also follow the overall decreasing trend, except near the end of the period in 2014, when a relatively high LA was measured. It is significant that the lakes appeared to be almost dry in 2009 for the first time in the past 30 years. These observations are consistent with a wetter climate in the late 1950s and 1960s, followed by a drier climate and long droughts during the period of this study.

Figure 4 indicated the time-series plot of LA, with a moving average of lake area added, along with a rainfall residual mass showing relatively dry and wet periods. The residual mass rainfall during the period 1987-2014 is clearly influenced by the following climatic features: the

\begin{tabular}{|c|c|c|c|c|c|}
\hline \multicolumn{2}{|c|}{ High-resolution reference image } & \multicolumn{2}{|c|}{ Classified image } & \multirow[t]{2}{*}{ Accuracy $(\%)$} & \multirow[t]{2}{*}{ Kappa coefficient } \\
\hline Source & Date of acquisition & Source sensor & Date of acquisition & & \\
\hline ADS-40 & 04/03/2008 & Landsat TM & 03/03/2008 & 88.4 & 0.76 \\
\hline WV-2 & $01 / 04 / 2010$ & Landsat TM & $25 / 03 / 2010$ & 92.8 & 0.85 \\
\hline Google Earth & 13/08/2013 & Landsat OLI & 17/08/2013 & 96.9 & 0.93 \\
\hline
\end{tabular}

Table 1 Accuracy of the classified Landsat images compared with high-resolution reference images 
Table 2 Validation of Landsat images with historical observations

\begin{tabular}{|c|c|c|c|c|c|}
\hline \multicolumn{3}{|l|}{ Historical observation } & \multicolumn{3}{|c|}{ Classified image results } \\
\hline Source of the observation & $\begin{array}{l}\text { Date of the } \\
\text { observation }\end{array}$ & Observation & $\begin{array}{l}\text { Source } \\
\text { sensor }\end{array}$ & $\begin{array}{l}\text { Date of } \\
\text { acquisition }\end{array}$ & $\begin{array}{l}\text { Lake area: measured } \\
\text { specific LA out of } \\
\text { maximum LA (in ha) }\end{array}$ \\
\hline $\begin{array}{l}\text { Caroline graham photographs } \\
\text { (Pells 2011) }\end{array}$ & $06 / 09 / 2010$ & Lake Baraba dry & Landsat TM & $10 / 09 / 2010$ & 0 out of 3.78 \\
\hline Water level (Pells 2016) & $01 / 10 / 2011$ & Lake Couridjah dry & Landsat TM & $15 / 10 / 2011$ & 0.0015 out of 4.92 \\
\hline Water level (Pells 2016) & $01 / 04 / 2010$ & Lake Werri Berri dry & Landsat TM & $25 / 03 / 2010$ & 0 out of 12.55 \\
\hline $\begin{array}{l}\text { Caroline graham photographs } \\
\quad \text { (Pells 2011) }\end{array}$ & 06/09/2010 & Lake Werri Berri dry & Landsat TM & $10 / 09 / 2010$ & 1.8 out of 12.55 \\
\hline Water level (Pells 2016) & $10 / 02 / 2011$ & Lake Werri Berri dry & Landsat TM & $01 / 02 / 2011$ & 0 out of 12.55 \\
\hline Water level (Pells 2016) & $01 / 10 / 2011$ & Lake Werri Berri dry & Landsat TM & $15 / 10 / 2011$ & 0 out of 12.55 \\
\hline Water level (Pells 2016) & $31 / 10 / 2009$ & Lake Nerrigorang dry & Landsat TM & $16 / 10 / 2009$ & 0 out of 4.32 \\
\hline Water level (Pells 2016) & $15 / 11 / 2010$ & Lake Nerrigorang dry & Landsat TM & $20 / 11 / 2010$ & 0 out of 4.32 \\
\hline NPWS photographs (Pells 2011) & $17 / 11 / 2010$ & Lake Nerrigorang dry & Landsat TM & $20 / 11 / 2010$ & 0 out of 4.32 \\
\hline Water level (Pells 2016) & $10 / 02 / 2011$ & Lake Nerrigorang dry & Landsat TM & $01 / 02 / 2011$ & 0 out of 4.32 \\
\hline NPWS photographs (Pells 2011) & $11 / 04 / 2011$ & Lake Nerrigorang dry & Landsat TM & $13 / 04 / 2011$ & 0.2 out of 4.32 \\
\hline
\end{tabular}

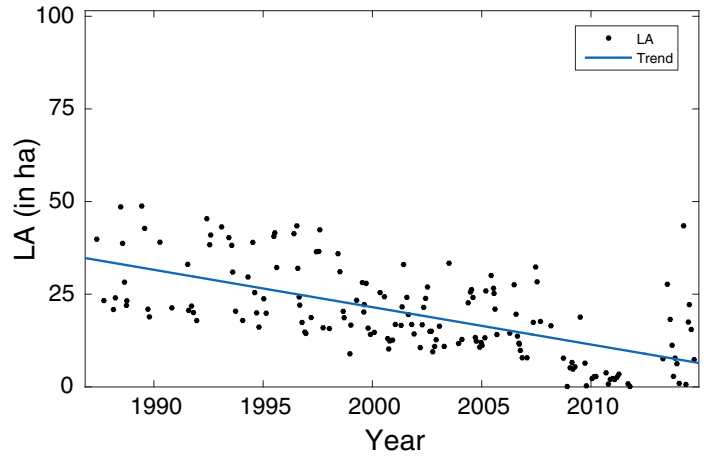

Fig. 3 Plot showing a decreasing linear trend of LA between 1987 and October 2014

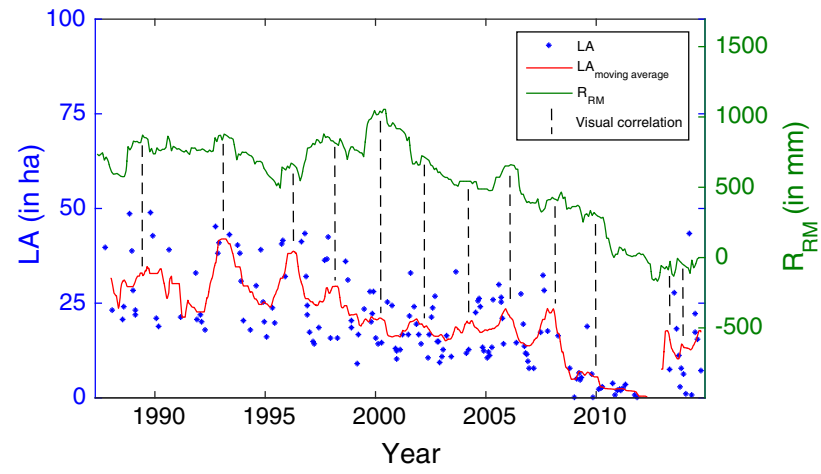

Fig. 4 Comparison of LA and $R_{\mathrm{RM}}$ and a moving average of LA (shown in red) between 1987 and October 2014

late 1980s and early 1990s period was relatively stable; 2010-2012 increasing with a strong La Nina event (BOM 2015); 1998-2000 increasing with a moderate La Nina event; 2000-2009 decreasing during the Millennium drought and 2009-2010 decreasing associated with a weak El Nino.

The moving average calculation of lake area (shown in red in Fig. 4) has a similar shape, but is not identical to the residual mass rainfall curve (shown in green in Fig. 4). The timings of maxima (e.g. 1990) and minima (e.g. 2010) lake areas were coincidental with maxima and minima residual rainfall readings (indicated by the vertical dashed lines in Fig. 4). An important change in the slope of residual rainfall mass occurred in August, 2012. The change from drier to wetter climatic conditions at this time was associated with significantly higher lake area. The increasing moving average of lake area calculated through NDWI is apparent in a partial recovery of lake area, and at least one point (29 March 2014) when the lakes were full or close to full.

The dominant factor influencing the total lake area during the study period was evidently rainfall. A possible influence of longwall mining and/or groundwater extraction across the area was not able to be identified in this dataset. On the other hand, drier conditions aligned with the occurrence of the Millennium drought, which could have been extended for several years. It is possible, if mining effects occurred, that hydrological effects lagged the completion of mining the closest longwall panels, and the minor or negligible effects were specific to each lake, rather than evident in average long-term data on total lake area. However, further analysis of lake area calculated from Landsat images with other factors (e.g. rainfall, evaporation, and flow data) was not possible due to a lack of historical hydrological data. Additional work could also 
be undertaken to determine the relative patterns of wetting and drying for individual lakes, particularly for cyclical (e.g. El Nino-La Nina) and non-cyclical (e.g. global warming) variations in climate.

The variation of $\mathrm{LA}_{\mathrm{MA}}$ and $R_{\mathrm{MA}}$ (Fig. 5) indicates a seasonal relationship with minimum for both in summer (December to February) and maximum during winter (June to August).

Regression analysis between $\mathrm{LA}_{\mathrm{MA}}$ and $R_{\mathrm{MA}}$ over 28 years produced a first order polynomial dependence with R-square of 0.8442 as shown in Fig. 6, with increasing scatter for low lake area. Based on this strong relationship, average monthly rainfall could be a good predictor of average monthly lake area. However, the months of smaller lake area in Fig. 6 also attribute to early summer season, when hydrological processes other than rainfall (e.g. evaporation, seepage) are dominant to reduce the lake area.

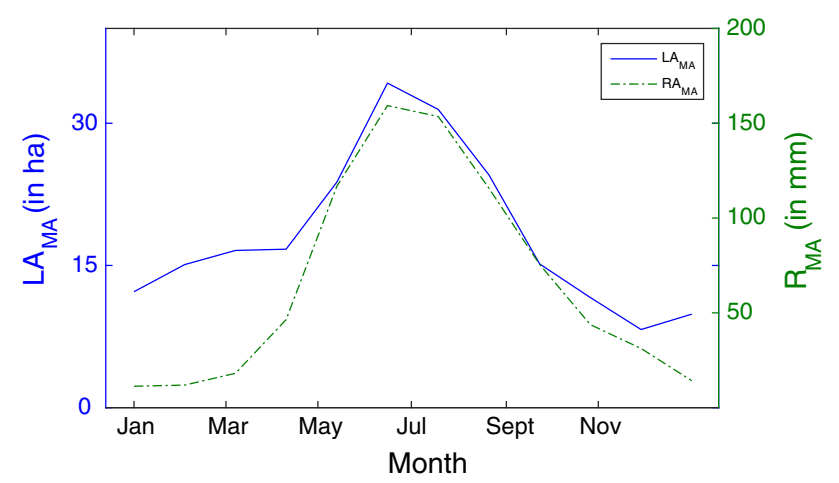

Fig. 5 Monthly variation of $\mathrm{LA}_{\mathrm{MA}}$ (in blue) and $R_{\mathrm{MA}}$ (in green) between 1987 and October 2014

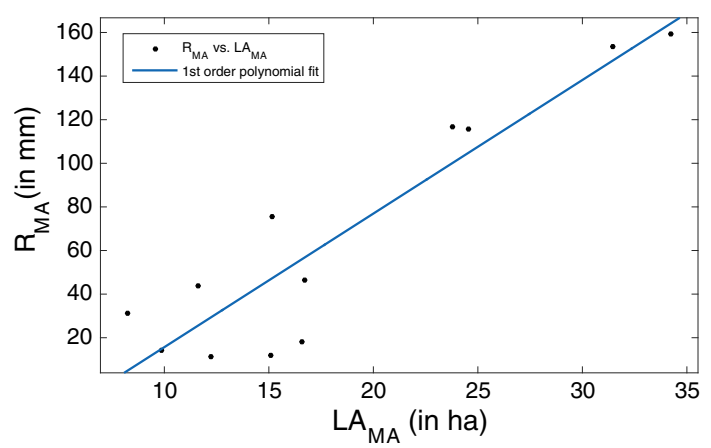

Fig. 6 Regression plot between average monthly rainfall $R_{\mathrm{MA}}$ and average monthly lake area $\mathrm{LA}_{\mathrm{MA}}$. The first order polynomial fit has an $\mathrm{R}$-square of 0.8442
The irregular intervals between suitable Landsat images have introduced some uncertainty into this analysis. A large lake area derived from an image on a specific date may actually be related to a large rainfall event that occurred weeks earlier minus evaporation and seepage losses that have occurred during the intervening time period. For example, Fig. 7 shows antecedent rainfall for the 100 days prior to the date of a Landsat image on the 15 th July 1995 when the calculated lake area was relatively high.

Depending on any time delay for inflow to the lakes, determined by hydrological monitoring and modelling, it is probable that the actual date of maximum lake area occurred on an unknown date during June rather than in July and that there is a variable but systematic error in the timing and magnitude of lake areas derived from remote sensing images that are not available more frequently. Table 3 provides further examples, with the time lag between the date of high-intensity rainfall and satellite observation varying from 52 to 72 days. The calculated lake areas would tend to be underestimated and lagging the date of actual maximum compared to continuous monitoring, if it was available during this period.

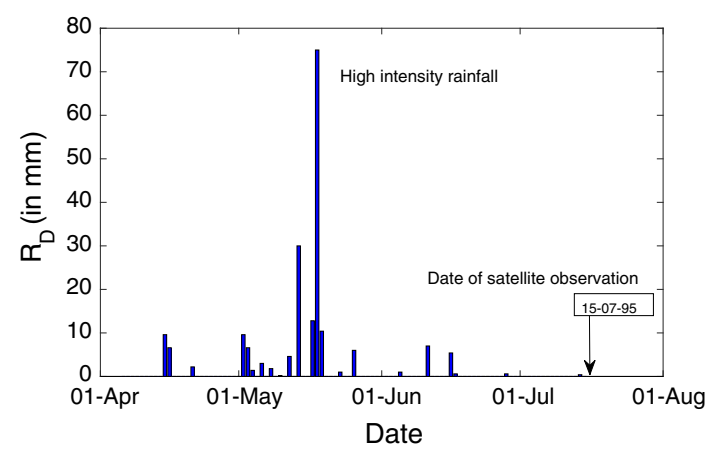

Fig. 7 Example of antecedent rainfall $R_{D}$ for the 100 days prior to date of Landsat image in July, 1995

Table 3 Comparison of time lag between high-intensity rainfall event and satellite observation for selected images

\begin{tabular}{lll}
\hline $\begin{array}{l}\text { Date of high-intensity rain } \\
\text { (rainfall in mm that day) }\end{array}$ & $\begin{array}{l}\text { Date of satellite- } \\
\text { based } \\
\text { observation }\end{array}$ & $\begin{array}{l}\text { Days between high } \\
\text { rain and observation }\end{array}$ \\
\hline $30-04-1988(93 \mathrm{~mm})$ & $26-06-1988$ & 57 \\
$01-04-1989(79.8 \mathrm{~mm})$ & $12-06-1989$ & 72 \\
$05-12-1992(66 \mathrm{~mm})$ & $06-02-1993$ & 63 \\
$18-05-1995(75 \mathrm{~mm})$ & $15-07-1995$ & 59 \\
\hline
\end{tabular}


These results highlight the potential benefits of remote sensing to augment a lack of historical information on lake area. There is a potential for further image and data analysis. For example, it would be possible to derive a time series of lake levels for each individual lake through highresolution images for comparison with modelling results. The commencement of automated water level monitoring as part of a new hydrological monitoring programme will provide the opportunity to verify an extended remote sensing dataset, setting measured water levels against derived lake areas. Real-time data from five lake monitoring stations are now available, having commenced progressively from December 2013 (NSW Government, 2015). The findings of this first reported application of remote sensing in the TLWA are consistent with the most recent inquiry (NSW Government. 2013), which reported that: "While it is possible that mining could have had a marginal effect on groundwater levels beneath the lakes, there is no definitive evidence that this has occurred. On the other hand, there is clear evidence for the drying of the lakes being coincident with a severe drought."

\section{Conclusion}

This study highlights the potential benefits of using satellite-based continuous multidecadal observations for hydrological monitoring of a wetland system in assessing the relative importance of environmental (including rainfall events and climatic trends), geological, and anthropogenic factors. Multidecadal Landsat images have been evaluated for the first time in the complex environment at Thirlmere Lakes to quantify the relationship between wetland area and rainfall. Within the 28-year period that was studied, it was evident that rainfall was the dominant factor in TLWA variability between 1987 and 2014, despite the otherwise limited historical information and baseline hydrological data. A significant advantage of remote sensing methods is to quantify the sources of error and uncertainty at key steps in the evaluation process, in tandem with field-based monitoring and modelling.

Importantly, this analysis has extended previous studies into a recent wetter period (from 2012 to October 2014), after a near-decade-long drought. Verified Landsat imagery analysis has provided early indications of an apparent recovery, or partial recovery, of TLWA from very low levels. It was found that if mining near the lakes has influenced TLWA, then its effects are likely to be minor compared to other factors such as rainfall. The results of this study are consistent with the findings of an earlier inquiry by Riley et al. (2012) in that rainfall is a dominant factor in TLWA variations. It is recommended that remote sensing analysis of TLWA compared with rainfall residual is extended in the future, with measured lake level-area relationships (e.g. derived from LiDAR survey). This study has demonstrated the utility of remote sensing for longterm monitoring of average changes over time for the total TLWA. However, the sensitivity and utility of remote sensing techniques could be further improved by application to each individual lake to evaluate variable hydrological responses across the area, specifically the lakes that may be more or less sensitive to possible anthropogenic effects. The extensive library of available satellite imagery going back decades combined with continual improvements in terms of resolution and sensors will further enhance the attractiveness of this technique to monitor temporal changes in wetlands and other habitats. Additional remote sensing studies should be combined with detailed investigations and hydrological monitoring of the lakes to further quantify the influence of human activities across the area, including groundwater extraction bores and mining operations.

Recent advancements in remote sensors, as well as platforms such as drones, now provide further opportunities for automated monitoring of key components of the hydrological balance, lake and swamp vegetation area and the health of swamp vegetation. Any differences in responses to wet and dry periods (e.g. the rate of drying) could be quantified with high-frequency temporal data, correlated with variations in groundwater extraction across the area and mining operations, and used to verify numerical models.

Acknowledgments This independent research was funded by the Australian Centre for Sustainable Mining Practices (ACSMP), School of Mining Engineering, UNSW, Australia, as a Ph.D. scholarship for the first author. The United States Geological Survey (USGS) is acknowledged for providing free access to the Landsat data. Additional historical lake level data were provided in kind by P. Pells.

\section{References}

Baghdadi N, Bernier M, Gauthier R, Neeson I (2001) Evaluation of C-band SAR data for wetlands mapping. Int J Remote Sens 22:71-88. doi:10.1080/014311601750038857

Barbier EB, Burgess JC, Folke C (1994) Paradise lost: the ecological economics of biodiversity. Earthscan Publications, London

BMCS (2012) Hut news: the vanishing Thirlmere Lakes. Blue Mountains Conservation Society, Conservation Hut, Wentworth Falls, New South Wales

BOM (2014) Bureau of meteorology daily rainfall data. http://www. bom.gov.au/climate/data/. Accessed 10 Oct 2014

BOM (2015) Bureau of meteorology, Australian Government, La Niña-Detailed Australian analysis. http://www.bom.gov.au/ climate/enso/lnlist/. Accessed 20 Jan 2015

Booth CJ (2006) Groundwater as an environmental constraint of longwall coal mining. Environ Geol 49:796-803. doi:10.1007/ s00254-006-0173-9

Bortels L, Chan JCW, Merken R, Koedam N (2011) Long-term monitoring of wetlands along the Western-Greek Bird Migration 
Route using Landsat and ASTER satellite images: amvrakikos Gulf (Greece). J Nat Conserv 19:215-223. doi:10.1016/j.jnc. 2011.01.004

Conway D, Allison E, Felstead R, Goulden M (2005) Rainfall variability in East Africa: implications for natural resources management and livelihoods. Philos Trans R Soc Lond A: Math Phys Eng Sci 363(1826):49-54

Daily GC (1997) Nature's services: societal dependence on natural ecosystems. Island Press, Washington

Dobson JE et al (1995) NOAA coastal change analysis program (CCAP): guidance for regional implementation. US Department of Commerce, National Oceanic and Atmospheric Administration, National Marine Fisheries Service, USA

Eamus D, Froend R (2006) Groundwater-dependent ecosystems: the where, what and why of GDEs. Aust J Bot 54:91-96. doi:10. 1071/bt06029

Ghatak DS (2010) Trade-off between conservation of environment and economic development? a case study of East Kolkata Wetland. International Institute of Social Studies, The Hague

Guo H, Adhikary DP, Craig MS (2008) Simulation of mine water inflow and gas emission during longwall mining. Rock Mech Rock Eng 42:25-51. doi:10.1007/s00603-008-0168-9

Harvey KR, Hill GJE (2001) Vegetation mapping of a tropical freshwater swamp in the Northern Territory, Australia: a comparison of aerial photography, Landsat TM and SPOT satellite imagery. Int J Remote Sens 22:2911-2925

Irish RR (2000) Landsat 7 science data users handbook. National Aeronautics and Space Administration, USA

Jenkins RB, Frazier PS (2010) High-resolution remote sensing of upland swamp boundaries and vegetation for baseline mapping and monitoring. Wetlands 30:531-540. doi:10.1007/s13157-0100059-1

Jensen JR, Christensen EJ, Sharitz R (1984) Nontidal wetland mapping in South Carolina using airborne multispectral scanner data. Remote Sens Environ 16:1-12. doi:10.1016/00344257(84)90023-3

Johnston RM, Barson MM (1993) Remote sensing of Australian wetlands: an evaluation of Landsat TM data for inventory and classification. Aust J Mar Freshw Res 44:235-252

Kay D, Waddington A, Page J, de Somer B (2006) Management of impacts of longwall mining under urban areas. In: Coal operators' conference, Australasian institute of mining and metallurgy, University of Wollongong, NSW, Australia, p 60

Kayastha N, Thomas V, Galbraith J, Banskota A (2012) Monitoring wetland change using inter-annual landsat time-series data. Wetlands 32:1149-1162. doi:10.1007/s13157-012-0345-1

Kebede S, Travi Y, Alemayehu T, Marc V (2006) Water balance of Lake Tana and its sensitivity to fluctuations in rainfall, Blue Nile basin, Ethiopia. J Hydrol 316(1-4):233-247

Mitsch WJ, Gosselink JG (1994) Wetlands, 2nd edn, vol 5. Land degradation and development, vol 1, Wiley. doi:10.1002/ldr. 3400050107

Mooney HA et al. (2005) Ecosystems and human well-being: wetland and water synthesis. Millennium ecosystem assessment, vol 358, Washington

Moser M, Prentice C, Frazier S (1996) A global overview of wetland loss and degradation. In: Paper presented at the proceedings of the 6th meeting of the conference of contracting parties, Brisbane, Australia, Ramsar Convention Bureau, Gland, Switzerland, 19-27 Mar 1996

Murray BBR, Zeppel MJ, Hose GC, Eamus D (2003) Groundwaterdependent ecosystems in Australia: it's more than just water for rivers. Ecol Manag Restor 4:110-113
NSW Government (2013) Thirlmere Lakes inquiry-review of the final report of the independent committee: NSW Chief Scientist and Engineer, New South Wales Government, Sydney

NSW Government (2015) Thirlmere Lakes water monitoring. Office of Environment and Heritage, New South Wales Government. http://www.environment.nsw.gov.au/water/thirlmere-lakes-waterdata.htm. Accessed 20 Jan 2015

Na X, Zang S, Zhang N, Cui J (2015) Impact of land use and land cover dynamics on Zhalong wetland reserve ecosystem, Heilongjiang Province, China. Int $J$ Environ Sci Technol 12:445-454. doi:10.1007/s13762-013-0398-6

Ozesmi SL, Bauer ME (2002) Satellite remote sensing of wetlands. Wetl Ecol Manag 10:381-402. doi:10.1023/A:1020908432489

Pells P (2011) Report on the water levels of Thirlmere Lakes. Pells Consulting, Central Coast

Ramsar Convention Secretariat (2011) Ecosystem services benefit factsheets. http://archive.ramsar.org/cda/en/ramsar-pubs-infoecosystem-services/main/ramsar/1-30-103\%5E24258_4000_0_ . Accessed 10 Oct 2014

Ramsar Convention Secretariat (2013) The Ramsar convention manual, 6th edn. RC Secretariat, Gland

Riley S, Finlayson M, Gore D, McLean W, Thomas K (2012) Thirlmere Lakes inquiry-final report of the Independent Committee. Office of Environment and Heritage, New South Wales Government, Sydney

Rundquist DC, Narumalani S, Narayanan RM (2001) A review of wetlands remote sensing and defining new considerations. Remote Sens Rev 20:207-226. doi:10.1080/0275725010 9532435

Sader SA, Ahl D, Liou WS (1995) Accuracy of Landsat-TM and GIS rule-based methods for forest wetland classification in Maine. Remote Sens Environ 53:133-144. doi:10.1016/0034-4257(95) 00085-F

Schädler S (2014) Long-term changes to water levels in Thirlmere Lakes-drivers and consequences. Master of Philosophy Thesis, School of Biological Earth and Environmental Sciences, University of New South Wales, New South Wales

Shanbhag AB, Borges SD (2008) Influence of innate wetland characteristics on site selection by wintering waterbirds in tropical freshwater wetlands. In: Paper presented at the proceedings of Taal2007: the 12th world lake conference, Jaipur

Shubho MTH, Islam SR, Ayon BD, Islam I (2014) An improved semiautomatic segmentation approach to land cover mapping for identification of land cover change and trend. Int J Environ Sci Technol 12:2593-2602. doi:10.1007/s13762-014-0649-1

Storey J, Scaramuzza P, Schmidt G, Barsi J (2005) Landsat 7 scan line corrector-off gap filled product development. Proc Pecora Sioux Falls S D USA 16:23-27

Tahmoor Coal (2012) Thirlmere Lakes-surface water balance assessment. Tahmoor Coal Pty Ltd, Bargo

Timms B (1992) The conservation status of athalassic lakes in New South Wales, Australia. Hydrobiologia 243:435-444

Tulbure MG, Broich M (2013) Spatiotemporal dynamic of surface water bodies using Landsat time-series data from 1999 to 2011. ISPRS J Photogramm Remote Sens 79:44-52. doi:10.1016/j. isprsjprs.2013.01.010

United States Geological Survey (2013) Using the USGS Landsat 8 product. United States Geological Survey, USA. http://landsat. usgs.gov/Landsat8_Using_Product.php. Accessed 09 Dec 2014

Vaezi A, Karbassi A, Valavi S, Ganjali M (2015) Ecological risk assessment of metals contamination in the sediment of the Bamdezh wetland. Iran Int J Environ Sci Technol 12:951-958 
van Dijk AI et al (2013) The Millennium Drought in southeast Australia (2001-2009): natural and human causes and implications for water resources, ecosystems, economy, and society. Water Resour Res 49:1040-1057

Wang G, Weng Q (2013) Remote sensing of natural resources. CRC Press, Boca Raton
Work EA Jr, Gilmer DS (1976) Utilization of satellite data for inventorying prairie ponds and lakes. Photogramm Eng Remote Sens 42:685-694

YCEO (2013) Converting digital numbers to top of atmosphere (ToA) reflectance, Center for Earth Observation, Yale University, New Haven, Connecticut, USA 